\title{
There's an app for that: technological solutionism as COVID-19 policy in the Global North
}

\author{
Linnet Taylor
}

TILT, Tilburg University

\section{Human Challenges, Technological Responses}

The COVID-19 pandemic took high-income countries entirely by surprise. Despite funding pandemic preparedness programs in Asia for more than 20 years, donor countries had not experienced an uncontrolled pandemic since HIV in the 1980s. When Ebola, Zika, SARS, and MERS threatened, countries outside the immediate geographic neighborhood or income level of those diseases' places of origin were left largely untouched. This led many northern countries not to take seriously the emergence of the novel coronavirus in 2019 as the existential threat it turned out to be. In contrast to the swift, comprehensive response of South-East Asian countries, authorities in Europe and the US assumed this coronavirus would behave like its predecessors SARS and MERS, which made their hosts seriously ill and sent them home, reducing their ability to infect others. Instead, the new virus presented itself with a very different epidemiology, hiding mostly unseen amongst the young and active while they infected those around them and ravaging the elderly and sick wherever it spread.

What happened next around the world was both harrowing and illuminating. Lacking protective material resources, human capacity for contact tracing, or understanding of the disease, policymakers in higherincome countries turned to technology for a miracle. The technology sector responded with history's most extensive hackathon, illuminating the mutual shaping of technology and public health policy. The most striking feature of the technological response to the pandemic has been the degree of solutionism (Morozov, 2013) driving it-the belief that complex problems can be solved by technological intervention alone.

\section{The Solutionist Approach to the Pandemic}

The driving example of solutionism during the first wave of the pandemic was the claim by a group of public health information specialists (Ferretti et al., 2020) that contact-tracing apps were the only way to stop the disease once it had spread out of control. The idea that an app could solve the pandemic was too attractive to ignore, and the policy take-up in higher-income countries was immediate and universal. Existing tracking technologies were repurposed for pandemic response as vendors took the opportunity of the newly created market to increase the visibility of their products. However, the apps developed soon demonstrated fundamental problems: they were vulnerable to false positives, where people would potentially receive many messages per day from their phone telling them to isolate based on contacts that may not, in fact, have been likely to infect them. Conversely, the apps would also miss many 
occasions when brief contact did in fact have a high likelihood of resulting in infection-they would be more likely to flag a ten-minute conversation with a coronavirus sufferer where both parties were wearing masks than an event where someone was directly sneezed on in a queue or a supermarket aisle.

These problems are compounded by the inaccuracy of coronavirus tests, which fail to detect infection between 20 and $60 \%$ of the time depending on the point at which the person is tested (Kucirka et al., 2020). They are further exacerbated by the frequency of asymptomatic infection, where in up to $80 \%$ of cases individuals themselves remain unaware they are infectious (Day, 2020). In addition to the problem of inaccurate information, apps were not imagined as support to human contact tracers, who were instead excluded from the picture almost entirely. Despite evidence from Asian countries that people would only self-isolate based on governmental requests to do so, conveyed by human contact tracers (Bloomberg, 2020), most high-income countries decided not to invest in training human contact tracers during the first months of 2020. In the Netherlands, the main infectious disease liaison for the public health authorities, Sjaak de Gouw, played down the value of human contact tracing, calling it pointless, while arguing against even testing people for the disease (an essential addition to contact tracing), saying, at the height of the first wave in April 2020: "what is the rationale behind the strategy of extensive testing? You do not prevent infections that way" (NRC, 2020a). ${ }^{1}$

With these beliefs driving public health policy advice, it would have been wise to question the value of an app as the main approach to combating the pandemic. For an app to receive valid information on whether people were infected, testing would have to be both available on demand and accurate enough that people would trust that information rather than facing continual automated demands for quarantine. Moreover, even if an automated system functioned perfectly, the rate of asymptomatic disease means it would be provided with inadequate data at best (Babones, 2020).

Why, then, was the focus so heavily on apps at a time when the remedy appeared to be material resources, behavior change, and building human capacity? Stafford Beer, in his work on organizational cybernetics (2004), advocated that, in order to analyze a technological system, we should ask what we observe it actually doing in the world, rather than what it is intended to do. If we apply this logic to the case of coronavirus apps in the Netherlands and other EU countries, success on several levels could be observed during the early months of 2020. First, the app development process fulfilled a psychological need for something constructive to do, providing both a goal and a clear deliverable for government and the technical community at a time when efforts to combat the pandemic were failing and an economydestroying lockdown was becoming the only option. Second, the process achieved a political function by distracting attention from governmental failures and the resulting death toll (NRC, 2020b). Third, they fulfilled a rhetorical function by supporting the public health authorities' narrative that testing and human contact tracing, which were not possible given the lack of material and trained human resources, were also not necessary (NRC, 2020a). Contact-tracing apps have not, at least so far, however, fulfilled the need to actually trace the contacts of people infected with COVID-19. As of July 2020, no country has been able to demonstrate that contact-tracing apps can work either in terms of adoption or effective isolation of the infected (Bloomberg, 2020).

\footnotetext{
1 "Wat is de rationale achter de strategie van het vele testen? Besmettingen voorkom je er niet mee."
} 
The app phase of the pandemic response also served a market-building function by orienting at least some of the policy response and public attention away from complex problems of technology provision (ventilators, mask manufacturing capacity, and other material resources) toward the simpler problem of repurposing existing population surveillance infrastructures. Along with the apps, over the first months of the pandemic many solutionist projects were proposed including systems to detect coronavirus infection from voices (Futurism, 2020), detecting infection clusters from sewage analysis using technology originally developed for detecting illegal drug labs (Peccia et al., 2020), and a barrage of biometric systems repurposed from immigration and crowd surveillance toward remote temperature sensing (CSO Online, 2020). Some of these efforts are more scientifically credible than others, but all have one feature in common: they replace prevention. Solutionism thrives on desperation, and the coronavirus has, in most of the world, provided a welcoming policy environment for it.

\section{Lessons of Solutionism}

There are higher-level lessons to be drawn from these proposals for pandemic technologies, perhaps most importantly that allowing the market to be the primary driver of technology development will result in technology that primarily serves the market rather than the needs of the public. However, the most relevant lessons for the ongoing effort to combat the pandemic are more immediate. In parallel with the European and US responses to the pandemic, a different set of strategies adopted by SouthEast Asian countries exists. These, ironically, were based substantially on guidance from institutions founded and funded in the Global North such as the WHO, philanthropies, and universities. They involved early response, immediate travel restrictions, intensive testing and contact tracing, and enforced quarantine where cases were found. Where these measures were taken, both infections and deaths remained strikingly low (BBC, 2020; Science, 2020). Despite a lack of material and technological resources, Vietnam has reported no COVID-19 deaths, and despite being both dense city-states and international travel hubs, Hong Kong has reported just seven deaths and Singapore twenty-six (Worldometer, 2020). Meanwhile in the Global North, the problem is already being reframed as technology acceptance and convincing people apps will work (e.g. Metova, 2020; Stanford news, 2020) although policy attention is, at the time of writing in summer 2020, finally reorienting toward material and human responses to the emergency.

Perhaps the most important lesson we can take with us into the 'new normal' of the pandemic from observing technological solutionism in the Global North is this: technology is important to pandemic response, but it must support rather than lead. The practical lessons of the pandemic are ones the North already knew, because it was busy teaching them in the South: the state of the art on how to combat a pandemic is to test, trace and isolate, and to do this exhaustively and accurately. Yet rather than apply thisknowledge, governments turned out to be more ready to listen to Northern innovators than to the public health experts, often internationally funded, in Southern pandemic-affected countries. The response shows that the North has not acquired the necessary capacity for pandemic response, namely flexibility, a focus on the most vulnerable, and human capacity supported by the digital rather than the other way around. Instead, we seem to have trained hard in believing our own rhetoric on technological innovation and the power of the market as solutions to truly existential challenges. 
Pre-publication draft 17.7.20

forthcoming in The New Common, eds. Emile Aarts, Hein Fleuren, Margriet Sitskoorn, Ton Wilthagen.

\section{References:}

Babones, S. (2020). Countries Rolling Out Coronavirus Tracking Apps Show Why They Can't Work. Foreign Policy. https://foreignpolicy.com/2020/05/12/coronavirus-tracking-tracing-apps-cantwork-south-korea-singapore-australia/

BBC. (2020, May 15). How “overreaction" made Vietnam a virus success. BBC News. https://www.bbc.com/news/world-asia-52628283

Beer, S. (2004). What is cybernetics? Kybernetes, 33(3/4), 9. https://doi.org/10.1108/03684920410523742

Bloomberg. (2020). Why Coronavirus Contact-Tracing Apps Aren't Ending the Pandemic. https://www.bloomberg.com/news/articles/2020-06-30/why-coronavirus-contact-tracing-appsaren-t-ending-the-pandemic

CSO Online. (2020, April 3). New coronavirus-era surveillance and biometric systems pose logistical, privacy problems. CSO Online. https://www.csoonline.com/article/3535194/new-coronavirusera-surveillance-and-biometric-systems-pose-logistical-privacy-problems.html

Day, M. (2020). Covid-19: Four fifths of cases are asymptomatic, China figures indicate. 2020(369:m1375). https://doi.org/10.1136/bmj.m1375

Ferretti, L., Wymant, C., Kendall, M., Zhao, L., Nurtay, A., Abeler-Dörner, L., Parker, M., Bonsall, D., \& Fraser, C. (2020). Quantifying SARS-CoV-2 transmission suggests epidemic control with digital contact tracing. Science, 368(6491). https://doi.org/10.1126/science.abb6936

Futurism. (2020). New app attempts to detect signs of COVID-19 using voice analysis. Futurism. https://futurism.com/neoscope/new-app-detects-covid19-voice

Kucirka, L. M., Lauer, S. A., Laeyendecker, O., Boon, D., \& Lessler, J. (2020). Variation in False-Negative Rate of Reverse Transcriptase Polymerase Chain Reaction-Based SARS-CoV-2 Tests by Time Since Exposure. Annals of Internal Medicine. https://doi.org/10.7326/M20-1495 
Pre-publication draft 17.7.20

forthcoming in The New Common, eds. Emile Aarts, Hein Fleuren, Margriet Sitskoorn, Ton Wilthagen.

Metova. (2020). New Survey Reveals Growing Acceptance Around COVID-19 Contact Tracing and Exposure Notification Apps. https://www.prnewswire.com/news-releases/new-survey-revealsgrowing-acceptance-around-covid-19-contact-tracing-and-exposure-notification-apps301083480.html

Morozov, E. (2013). To save everything, click here: The folly of technological solutionism (First edition). PublicAffairs.

NRC. (2020a). Infectieziektebestrijder GGD is aan zet, maar die twijfelt. NRC. https://www.nrc.nl/nieuws/2020/04/22/het-is-tijd-voor-de-klassieke-infectiebestrijders-de-ggda3997610

NRC. (2020b, June 19). Hoe Nederland de controle verloor: De corona-uitbraak van dag tot dag. NRC. https://www.nrc.nl/nieuws/2020/06/19/hoe-nederland-reageerde-op-het-nieuwe-virus-uitchina-van-niks-aan-de-hand-tot-blinde-paniek-a4003075

Peccia, J., Zulli, A., Brackney, D. E., Grubaugh, N. D., Kaplan, E. H., Casanovas-Massana, A., Ko, A. I., Malik, A. A., Wang, D., Wang, M., Warren, J. L., Weinberger, D. M., \& Omer, S. B. (2020). SARSCoV-2 RNA concentrations in primary municipal sewage sludge as a leading indicator of COVID19 outbreak dynamics [Preprint]. Epidemiology. https://doi.org/10.1101/2020.05.19.20105999

Science. (2020, April 13). 'Suppress and lift': Hong Kong and Singapore say they have a coronavirus strategy that works. Science | AAAS. https://www.sciencemag.org/news/2020/04/suppressand-lift-hong-kong-and-singapore-say-they-have-coronavirus-strategy-works

Stanford news. (2020, April 9). Stanford researchers help develop privacy-focused coronavirus alert app. Stanford News. https://news.stanford.edu/2020/04/09/stanford-researchers-help-developprivacy-focused-coronavirus-alert-app/

Worldometer. (2020). Singapore Coronavirus: 44,122 Cases and 26 Deaths - Worldometer. https://www.worldometers.info/coronavirus/country/singapore/ 
Pre-publication draft 17.7.20

forthcoming in The New Common, eds. Emile Aarts, Hein Fleuren, Margriet Sitskoorn, Ton Wilthagen. 